\title{
Dissociable effects of monoamine reuptake inhibitors on distinct forms of impulsive behavior in rats
}

\author{
Petra J. J. Baarendse • Louk J. M. J. Vanderschuren
}

Received: 10 June 2011 / Accepted: 4 November 2011 / Published online: 3 December 2011

(C) The Author(s) 2011. This article is published with open access at Springerlink.com

\begin{abstract}
Rationale High levels of impulsivity are a core symptom of psychiatric disorders such as ADHD, mania, personality disorders and drug addiction. The effectiveness of drugs targeting dopamine (DA), noradrenaline (NA) and/or serotonin (5-HT) in the treatment of impulse control disorders emphasizes the role of monoaminergic neurotransmission in impulsivity. However, impulsive behavior is behaviorally and neurally heterogeneous, and several caveats remain in our understanding of the role of monoamines in impulse control.

Objectives This study aims to investigate the role of DA, NA and 5-HT in two main behavioral dimensions of impulsivity.

Methods The effects of selective DA (GBR12909; 2.5$10 \mathrm{mg} / \mathrm{kg}$ ), NA (atomoxetine; 0.3-3.0 mg/kg) and 5-HT (citalopram; $0.3-3.0 \mathrm{mg} / \mathrm{kg}$ ) reuptake inhibitors as well as amphetamine $(0.25-1.0 \mathrm{mg} / \mathrm{kg})$ were evaluated on impulsive action in the five-choice serial reaction time task (5-CSRTT) and impulsive choice in the delayed reward task (DRT). In the 5-CSRTT, neuropharmacological challenges were performed under baseline and long intertrial interval (ITI) conditions to enhance impulsive behavior in the task.
\end{abstract}

P. J. J. Baarendse • L. J. M. J. Vanderschuren

Department of Neuroscience and Pharmacology,

Rudolf Magnus Institute of Neuroscience, UMC Utrecht,

Universiteitsweg 100,

3584 CG Utrecht, The Netherlands

L. J. M. J. Vanderschuren $(\square)$

Department of Animals in Science and Society, Division of

Behavioural Neuroscience, Faculty of Veterinary Medicine,

Utrecht University,

Utrecht, The Netherlands

e-mail: 1.j.m.j.vanderschuren@umcutrecht.nl
Results Amphetamine and GBR12909 increased impulsive action and perseverative responding and decreased accuracy and response latency in the 5-CSRTT. Atomoxetine increased errors of omission and response latency under baseline conditions in the 5-CSRTT. Under a long ITI, atomoxetine also reduced premature and perseverative responding and increased accuracy. Citalopram improved impulse control in the 5-CSRTT. Amphetamine and GBR12909, but not citalopram or atomoxetine, reduced impulsive choice in the DRT.

Conclusions Elevation of DA neurotransmission increases impulsive action and reduces impulsive choice. Increasing NA or 5-HT neurotransmission reduces impulsive action.

Keywords Impulsivity · Delayed reward · Five-choice serial reaction time task $\cdot$ Dopamine $\cdot$ Serotonin $\cdot$ Noradrenaline

\section{Introduction}

Exaggerated impulsive behavior very often has undesirable consequences. As such, impulsivity is prominent in the symptomatology of a variety of psychiatric disorders such as attention deficit/hyperactivity disorder (ADHD), drug addiction, problem gambling, mania and personality disorders (American Psychiatric Association 2000; Chamberlain and Sahakian 2007; Moeller et al. 2001). Moreover, impulsivity may be a behavioral marker for enhanced vulnerability to drug addiction. Poor response inhibition or enhanced impulsive decision making predisposes adolescents for smoking, alcoholism and substance abuse (Audrain-McGovern et al. 2009; Nigg et al. 2006). Consistently, animal studies have shown that high impulsivity predicts the vulnerability to alcohol consumption, cocaine self-administration and nicotine-seeking behavior (Dalley et al. 2007; Diergaarde et 
al. 2008; Perry et al. 2005; Poulos et al. 1995). It is now widely recognized that impulsivity consists of various, mostly independent behavioral dimensions that can be neuroanatomically and neuropharmacologically dissociated (Dalley et al. 2011; Eagle and Baunez 2010; Evenden 1999; Pattij and Vanderschuren 2008; Winstanley 2011). In general, two main subtypes of impulsive behavior are distinguished, i.e., impulsive choice and impulsive action. Impulsive choice refers to the inability to delay gratification, which is behaviorally apparent as a preference for a small, immediate gain over a larger reward that one has to wait for. Impulsive action comprises behavior resulting from a deficit in the ability to withhold responding or stop ongoing behavior. Both behavioral subtypes of impulsivity appear in the patient population and these can be studied in preclinical models with high translational value (Evenden 1999; Moeller et al. 2001; Solanto et al. 2001; Winstanley 2011).

Different classes of drugs are used in the treatment of disorders characterized by disrupted impulse regulation such as ADHD, personality disorders and problem gambling. The psychostimulant drugs amphetamine (Adderall ${ }^{\mathrm{TM}}$ ) and methylphenidate (Ritalin ${ }^{\mathrm{TM}}$, Concerta ${ }^{\mathrm{TM}}$ ) are the first-choice treatment for ADHD, whereas the selective noradrenaline reuptake inhibitor atomoxetine (Strattera $\left.{ }^{\circledR}\right)$ is a widely used alternative (Biederman and Faraone 2005). The therapeutic use of these drugs has sparked great interest in the role of monoaminergic neurotransmission in impulsivity. The primary mode of action of amphetamine is to enhance monoaminergic neurotransmission by blocking the reuptake and evoking the release of dopamine (DA), noradrenaline (NA) and, to a lesser extent, serotonin (5-hydroxytryptamine, 5-HT) (Kuczenski and Segal 1989; Kuczenski et al. 1995; Ritz and Kuhar 1989; Rothman et al. 2001; Seiden et al. 1993; Sulzer et al. 1995). Administration of amphetamine has been shown to decrease impulsive choice in delaydiscounting paradigms (Barbelivien et al. 2008; Cardinal et al. 2000; De Wit et al. 2002; Isles et al. 2003; Richards et al. 1999; Sun et al. 2011; Van Gaalen et al. 2006b; Wade et al. 2000; Winstanley et al. 2003, but see Evenden and Ryan 1996) but to increase premature responding, an index of impulsive action, in the five-choice serial reaction time task (5-CSRTT; Cole and Robbins 1987; 1989; Harrison et al. 1997; Murphy et al. 2008; Paterson et al. 2011; Pattij et al. 2007; Sun et al. 2011; Van Gaalen et al. 2006a). Pharmacological analysis of the effects of amphetamine has indicated that DA neurotransmission plays an important, opposing role in the modulation of impulsive action and impulsive choice (Cole and Robbins 1989; Pattij et al. 2007; van Gaalen et al. 2006a, 2006b, 2009). Atomoxetine is a potent NA reuptake inhibitor with no appreciable affinity for the DA or 5-HT transporter (Bolden-Watson and Richelson 1993), which has been shown to be effective in the treatment of ADHD (Kratochvil et al. 2006; Simpson and Perry 2003; Spencer et al. 2002; Wilens et al. 2006). Although selective inhibition of NA reuptake has been reported to have beneficial effects on impulsive action in the 5-CSRTT (Blondeau and DelluHagedorn 2007; Navarra et al. 2008; Paine et al. 2007; Paterson et al. 2011; Robinson et al. 2008; Sun et al. 2011; Van Gaalen et al. 2006a), its effects on impulsive choice are inconclusive (Robinson et al. 2008; Sun et al. 2011; Van Gaalen et al. 2006b). Interestingly, 5-HT was the first neurotransmitter system to be implicated in impulsivity (Linnoila et al. 1983; Soubrié 1986). Selective 5-HT reuptake inhibitors (SSRIs) are not regularly prescribed as therapeutic drugs for ADHD (Biederman and Faraone 2005; Elia et al. 1999; Fone and Nutt 2005; Kutcher et al. 2004), although they are used for the treatment of other disorders associated with poor impulse control such as problem gambling, sexual addiction, personality disorders and impulsive aggression (Coccaro and Kavoussi 1997; Hollander and Rosen 2000). Remarkably, the effects of SSRIs on different forms of impulsive behavior have not been characterized in depth (Bari et al. 2009; Evenden and Ryan 1996).

Although the role of monoamine neurotransmission in impulsive behavior has been widely investigated, several caveats remain. First, as mentioned above, the consequences of selective blockade of the 5-HT transporter for impulsive behavior are largely unknown. Second, beneficial effects of selective NA reuptake inhibitors on impulsive action (as assessed in the 5-CSRTT and stop signal task) have been consistently reported by different studies, but its effects on impulsive choice are inconclusive. Third, in studies on impulsive action using the 5-CSRTT, welltrained animals are used, which often display very low levels of impulsivity. This makes it easy to detect impairments in impulse control but leaves relatively little room to observe reductions in premature responding, which is most relevant from a therapeutic point of view. The present study sought to further characterize the role of monoamine neurotransmission in impulsive behavior, taking these caveats into account. To that aim, we investigated the effects of selective inhibitors of the reuptake of DA (GBR12909), NA (atomoxetine) and 5-HT (citalopram) on two main behavioral dimensions of impulsivity in rats. Impulsive action was studied using the 5-CSRTT (Carli et al. 1983; Robbins 2002), and the delayed reward task (DRT; Evenden and Ryan 1996) was used to measure impulsive choice. Amphetamine was also included as its effects on impulsive behavior have been well described (Eagle and Baunez 2010; Pattij and Vanderschuren 2008). To increase the possibility to observe drug-induced reductions in impulsive action, we performed neuropharmacological challenges in the 5-CSRTT under both baseline as well as long intertrial interval (ITI) conditions. The use of a long ITI, in which the animal unexpectedly has to wait longer for the instruction signal to appear, enhances levels 
of impulsive action in the 5-CSRTT (Dalley et al. 2002; Navarra et al. 2008; Paterson et al. 2011). Not only does a long ITI evoke higher levels of premature responding, it may also be that performance under baseline conditions relies on different neural and cognitive processes than responding under novel, challenging circumstances. For example, NA neurotransmission appears to be especially engaged when task contingencies unexpectedly change (Cole and Robbins 1992; Dalley et al. 2001; Sirviö et al. 1993). Thus, drug effects under baseline and long ITI conditions in the 5-CSRTT may be qualitatively or quantitatively different.

\section{Materials and methods}

\section{Subjects}

Male Lister Hooded rats (Harlan CPB, Horst, The Netherlands), weighing 200-250 $\mathrm{g}$ at the beginning of the experiment, were housed two per cage under reversed lighting conditions (lights on from 19.00 to $07.00 \mathrm{~h}$ ). After 2 weeks of habituation, rats were placed on a restricted diet of $14 \mathrm{~g}$ of standard rat chow per day and body weights were monitored on a weekly basis. Feeding occurred in the rats' home cages at the end of the experimental day. All experiments were approved by the Animal Ethics Committee of Utrecht University and were conducted in agreement with Dutch laws (Wet op de Dierproeven, 1996) and European regulations (Guideline 86/609/EEC).

\section{Behavioral apparatus}

Behavioral testing for all experiments was conducted in 16 identical operant conditioning chambers $(30.5 \times 24 \times 21 \mathrm{~cm}$; Med Associates, St. Albans, VT, USA) enclosed in sound attenuating boxes. The boxes were equipped with a fan to provide ventilation and to mask extraneous noise. Set in the curved wall of each box was an array of five holes. Each nose poke unit was equipped with an infrared detector and a yellow light-emitting diode stimulus light. Food pellets (45 mg, Formula P; Bio-Serv) could be delivered at the opposite wall via a dispenser. The chamber could be illuminated by a white house light mounted in the center of the roof. Online control of the apparatus and data collection were performed using MEDPC version 1.17 (Med Associates).

\section{Behavioral procedures}

A detailed description of the 5-CSRTT and DRT procedure has been provided previously (Van Gaalen et al. 2006a; Van Gaalen et al. 2006b, respectively). Separate groups of animals were trained for each experiment. For both behavioral paradigms, similar habituation and magazine training protocols were followed. This protocol consisted of a habituation exposure to the operant chambers for two daily 30-min sessions, during which sucrose pellets were placed in the response holes and food magazine. Subsequently, in the next two sessions, a total of 75 pellets were delivered with a random interval to allow the animals to associate the sound of pellet delivery with reward. This procedure was followed by magazine shaping, in which animals were trained to make a nose poke into an illuminated response hole to earn reward. The spatial location of the stimulus lights was adjusted according to the experimental paradigm. Each session of magazine training consisted of 100 trials and lasted approximately $30 \mathrm{~min}$. Five sessions were scheduled per week (one session per day, Monday-Friday) during the dark phase of the light/dark cycle.

\section{Five-choice serial reaction time task}

Rats were trained to detect and respond to a brief visual stimulus presented randomly in one of the five nose poke units to obtain a food reward. A trial started with an ITI of $5 \mathrm{~s}$, followed by 1-s illumination of one of the five apertures and 2-s limited hold. Following a nose poke in the illuminated aperture, i.e., a correct response, animals were rewarded with the delivery of one food pellet $(45 \mathrm{mg}$, Formula P, Research Diets) in the food magazine. During the training session, stimulus duration was set at $32 \mathrm{~s}$ and was gradually decreased over sessions to $1 \mathrm{~s}$ until animals reached stable baseline performance (accuracy, $>80 \%$ correct choice and $<20 \%$ errors of omission). Each daily session consisted of 100 discrete trials or $30 \mathrm{~min}$, whichever occurred first. A nose-poke response into a nonilluminated aperture, i.e., an incorrect response as well as failure to respond within $5 \mathrm{~s}$ after the onset of the stimulus, i.e., an error of omission, resulted in no food delivery and a time-out period with the house light extinguished for $5 \mathrm{~s}$. Nose pokes made during the ITI, i.e., before the onset of the stimulus (premature responses) were recorded as a measure of impulsivity and resulted in a $5 \mathrm{~s}$ time-out and no food reward. Perseverative responses, i.e., repeated responding during the presentation of the stimulus, were measured but did not have any programmed consequences. The following behavioral measures were recorded: (1) premature responses, i.e., number of responses into one of the holes during the ITI preceding stimulus presentation; (2) accuracy, i.e., percentage of correct responses [(number correct responses) / (correct+incorrect responses) $\times 100$ ]; (3) latency of correct responses, i.e., the mean time between stimulus onset and nose poke in the illuminated unit; (4) omission errors, i.e., the total number of omitted trials during a session; and (5) perseverative responses after correct choice. 
Following acute drug administration under baseline conditions, a cohort of rats was used for pharmacological manipulation under long ITI conditions. During these sessions, the ITI was extended to $7 \mathrm{~s}$ to provoke impulsive behavior (Dalley et al. 2002). The long ITI session consisted of 100 trials (ITI $7 \mathrm{~s}$, stimulus duration $0.5 \mathrm{~s}$ ) per session and was repeated once a week. The long ITI days were at all times preceded and followed by two baseline days (ITI $5 \mathrm{~s}$, stimulus duration $0.5 \mathrm{~s}$ ) to avoid habituation to the long ITI.

\section{Delayed reward paradigm}

Rats were faced with a choice between a small, immediate food reward and a larger but delayed food reward. Ultimately, the delayed option is more beneficial, but the subjective value of the large food reward declines with increasing delay to its delivery (Logue 1988).

In the final stage of the task, a session was divided into five blocks of 12 trials. Each block started with two forced trials in which, after initiating the trial by a nose poke into the center hole, either the left or the right hole was illuminated in a counterbalanced fashion. For the next 10 trials, the animals had a free choice and both the left and right units were illuminated. Nose poking into one position resulted in the immediate delivery of a small reinforcer (one food pellet), whereas a nose poke into the other position resulted in the delivery of a large, but delayed, reinforcer (four food pellets). Over sessions, the delays for the large reinforcer were progressively increased within a session from 0 to $10,20,40$ and $60 \mathrm{~s}$ per block. After delivery of the reinforcer or the choice phase time elapsed, an ITI commenced until the next trial started. As the trial time was fixed, the ITI duration depended on the duration of the delay. The positions associated with the small and large reinforcers were always the same for each individual but counterbalanced for the group. The behavioral measure to assess task performance, i.e., the percentage preference for the large reinforcer as a function of delay, was calculated as the [(number of choices for the large reinforcer) / (number choices large + small reinforcers $) \times 100]$. Furthermore, no response during the choice phase within $10 \mathrm{~s}$ was counted as an omission and the total number of omitted choice trials per block of 10 trials within a session was calculated.

\section{Drugs}

(+)-Amphetamine sulphate was purchased from O.P.G. (Utrecht, The Netherlands). GBR12909 dihydrochloride, atomoxetine hydrochloride and citalopram hydrobromide were obtained from Tocris Bioscience (UK). All drug doses were calculated as salt, dissolved in $0.9 \%$ saline (amphetamine, atomoxetine, and citalopram) or sterile water
(GBR12909). Drugs were freshly prepared each day before testing and injected intraperitoneally (i.p.) in a volume of $1 \mathrm{ml} /$ $\mathrm{kg}$ body weight. Drug tests were conducted on Tuesdays and Fridays with baseline training sessions on the other weekdays. Before the first test day, all animals had been habituated twice to i.p. saline injections. Drugs were administered according to a Latin square design and each animal received a maximum of two different drugs. In addition, in a subgroup of rats pharmacological manipulations were tested in the 5-CSRTT under a long ITI of $7 \mathrm{~s}$ once a week according to a Latin square design with baseline training sessions (intertrial interval of $5 \mathrm{~s}$ ) in between.

\section{Statistical analysis}

All data are presented as means and standard errors of the mean and analyzed using SPSS for Windows, version 15.0. The data of the delayed reward task were subjected to an arcsin transformation before statistical analysis (McDonald 2009). In the DRT, animals that did not show a delaydependent curve in their choice behavior $(0 \%$ choice for large reward at $0 \mathrm{~s}$ delay, $100 \%$ choice for large reward at 40 and $60 \mathrm{~s}$ delay) were excluded from the experiment. Data were analyzed by one- (5-CSRTT) or two-factor (DRT) repeated-measures ANOVAs with drug treatment (5-CSRTT, DRT) and delay to large reinforcer (DRT) as within-subjects variables. If the outcome of the repeated-measures ANOVA yielded significant effects of dose or dose $\times$ delay at $p<0.05$ level, further post-hoc analysis was performed using paired samples $t$-tests. Pharmacological effects on 5-CSRTT performance under a long ITI were analyzed using paired samples $t$-tests (vehicle versus drug treatment).

\section{Results}

Effect of amphetamine and monoamine reuptake inhibitors on 5-CSRTT performance under baseline conditions

As depicted in Fig. 1a and Table 1, amphetamine significantly increased the number of premature responses and perseverative responses in the 5-CSRTT $[F(3,45)=$ $13.12, p<0.001$ and $F(3,45)=3.64, p<0.05$, respectively]. Post-hoc analysis revealed that the increase of premature and perseverative responses was significant at all tested doses $(p<0.01$ and $p<0.05$, respectively). In addition to the effect on impulsivity, systemic administration of amphetamine reduced accuracy, i.e., percentage of correct responses at all doses $[F(3,45)=8.82, p<0.001]$, whereas the response latency was only reduced at a dose of $0.5 \mathrm{mg} /$ $\mathrm{kg}$ (Table 1) $[F(3,45)=3.37, p<0.05]$. Errors of omission were differentially affected by amphetamine; as $0.25 \mathrm{mg} / \mathrm{kg}$ of amphetamine reduced the amount of errors of omission, 
Fig. 1 Effects of amphetamine (a), the selective DA reuptake inhibitor GBR12909 (b), the selective NA reuptake inhibitor atomoxetine (c) and the selective 5-HT reuptake inhibitor citalopram (d) on premature responding, i.e., impulsive action under baseline conditions (visual stimulus presented $5 \mathrm{~s}$ after trial initiation) in the 5-CSRTT. In total, $n=16$ animals were included in the analysis. Asterisk indicates $p<0.05$ and two asterisks indicates $p<0.01$ compared to vehicle treatment (paired samples $t$-test). All data are expressed as mean \pm SEM
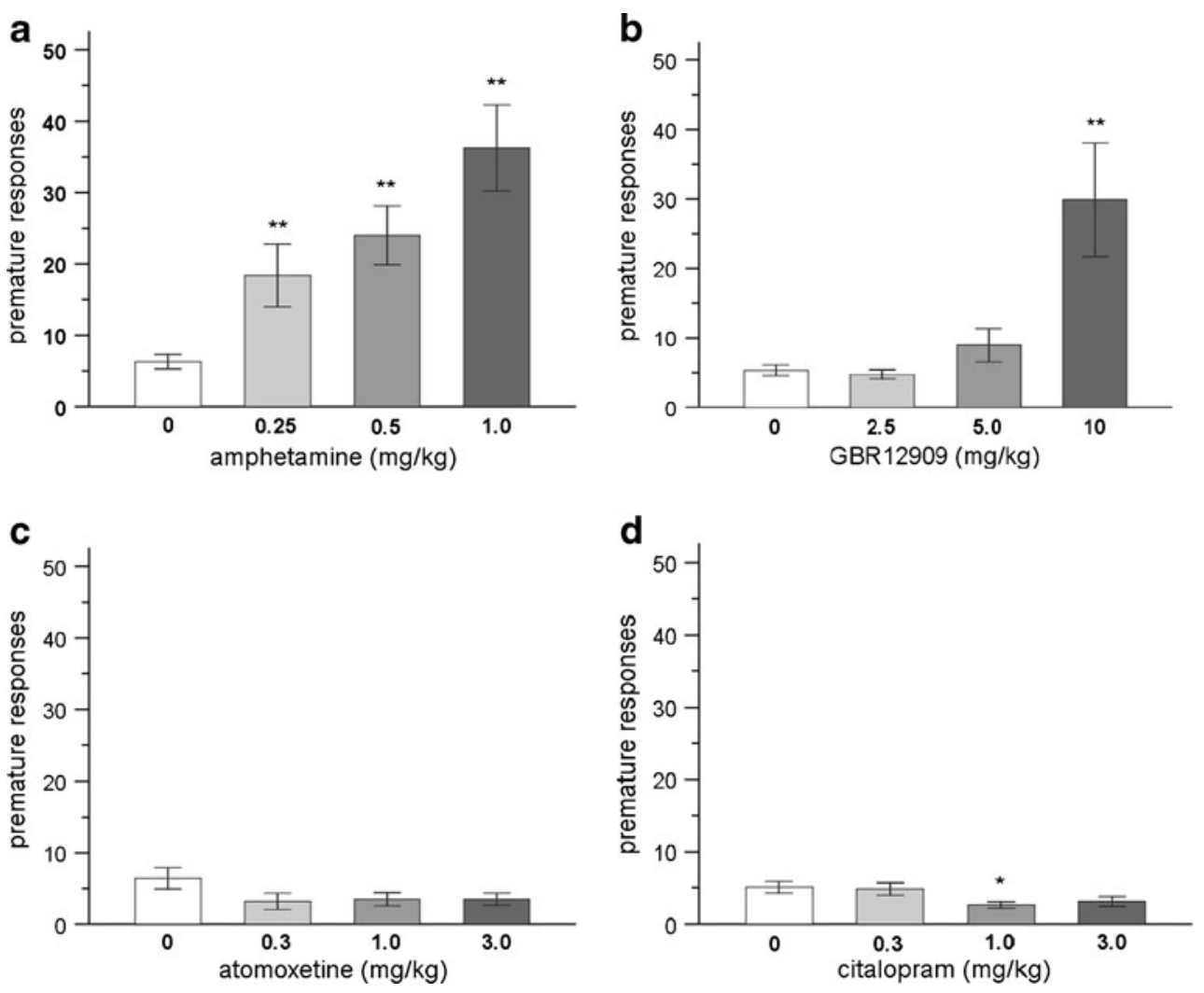

no effect was found at the intermediate dose of $0.5 \mathrm{mg} / \mathrm{kg}$ and $1 \mathrm{mg} / \mathrm{kg}$ of amphetamine resulted in a significant increase (Table 1) $[F(3,45)=10.49, p<0.001]$.

Systemic administration of the selective DA reuptake inhibitor GBR12909 resulted in enhanced premature and perseverative responses at a dose of $10 \mathrm{mg} / \mathrm{kg}$ (Fig. $1 \mathrm{~b}$ and Table 1) $[F(3,45)=8.46, p<0.007$ and $F(3,45)=10.26$, $p<0.004$, respectively]. At this dose, the percentage of correct responses and response latency were reduced (Table 1) $[F(3,45)=6.02, p<0.01$ and $F(3,45)=3.93$, $p=0.01$, respectively]. GBR 12909 had no effect on errors of omission $[F(3,45)=2.23, \mathrm{NS}]$.

Atomoxetine, the selective NA reuptake inhibitor, enhanced the errors of omission and slowed response latency at all tested doses without affecting impulsive behavior (Fig. 1c and Table 1) $[F(3,45)=26.43, p<0.001$, $F(3,45)=23.22, p<0.001, F(3,45)=2.54$, NS, respectively]. The other parameters of 5-CSRTT performance were unaffected by atomoxetine treatment under baseline conditions [correct responses: $F(3,45)=2.23$, NS and perseverative responses: $F(3,45)=0.8, \mathrm{NS}]$.

Premature responding was decreased after treatment with the selective 5-HT reuptake inhibitor citalopram at the intermediate dose of $1.0 \mathrm{mg} / \mathrm{kg}$ (Fig. 1d) $[F(3,45)=2.98$, $p<0.05]$, whereas the response latency was increased at a dose of $1.0 \mathrm{mg} / \mathrm{kg}$ and $3.0 \mathrm{mg} / \mathrm{kg}[F(3,45)=2.79, p=0.05]$. Further comparisons indicated that accuracy, errors of omissions and perseverative responses were unaffected by citalopram $[F(3,45)=0.23$, NS, $F(3,45)=0.99$, NS, $F(3,45)=$ 1.97, NS, respectively].

Effect of amphetamine and monoamine reuptake inhibitors on 5-CSRTT performance under long ITI conditions

Under long ITI conditions in the 5-CSRTT, the effects of monoamine reuptake inhibitors were tested at a dose that affected impulsive behavior under baseline conditions, i.e., $10 \mathrm{mg} / \mathrm{kg}$ GBR12909 and $1 \mathrm{mg} / \mathrm{kg}$ citalopram. For atomoxetine, which did not alter impulsive behavior under baseline conditions, the highest dose was used (i.e., $3 \mathrm{mg} /$ $\mathrm{kg})$. An intermediate dose of amphetamine $(0.5 \mathrm{mg} / \mathrm{kg})$ was used as this dose had no effect on the errors of omission under baseline conditions but did markedly increase impulsive behavior in the 5-CSRTT (Table 1).

Similar to baseline conditions, amphetamine $(0.5 \mathrm{mg} / \mathrm{kg})$ and GBR12909 (10 mg/kg) increased the amount of premature and perseverative responses and attenuated accuracy under long ITI conditions (Fig. 2a, b) [premature responses: $d f=15, t=-4.07, p=0.001$ and $d f=14, t=-3.49$, $p=0.01$, perseverative responses: $d f=15, t=-3.21, p<0.01$ and $d f=14, t=-2.50, p<0.05$, correct responses: $d f=15, t=$ 2.70, $p<0.05$ and $d f=14, t=2.52, p<0.05$, respectively]. In addition, GBR12909 (10 mg/kg) decreased response latency, whereas amphetamine had no effect on this parameter $[d f=$ $14, t=2.91, p=0.01$ and $d f=15, t=-0.44$, NS, respectively]. No effect of amphetamine and GBR12909 was 
Table 1 Effects of amphetamine, GBR12909, atomoxetine and citalopram on behavioral performance (accuracy, omissions, premature and perseverative responses, response latency) under baseline conditions (visual stimulus presented $5 \mathrm{~s}$ after trial initiation) in the 5 -
CSRTT. In total, $n=16$ animals were included in the analysis. ${ }^{*} p<0.05$ and $* * p<0.01$ compared to vehicle treatment (paired samples $t$-test). All data are expressed as mean \pm SEM

\begin{tabular}{|c|c|c|c|c|c|}
\hline & Correct responses & Errors of omission & Premature responses & Perseverative responses & Response latency (s) \\
\hline \multicolumn{6}{|c|}{ Amphetamine } \\
\hline Veh & $90.8 \pm 1.4$ & $17.9 \pm 1.6$ & $6.3 \pm 1.0$ & $13.8 \pm 2.4$ & $0.71 \pm 0.03$ \\
\hline $0.25 \mathrm{mg} / \mathrm{kg}$ & $85.2 \pm 2.2 *$ & $12.4 \pm 1.3^{*}$ & $18.4 \pm 4.4^{* *}$ & $23.7 \pm 4.9^{*}$ & $0.66 \pm 0.02$ \\
\hline $0.5 \mathrm{mg} / \mathrm{kg}$ & $82.9 \pm 2.3^{*}$ & $16.2 \pm 2.3$ & $24.0 \pm 4.1 * *$ & $23.8 \pm 5.7 *$ & $0.6 \pm 0.02 *$ \\
\hline $1.0 \mathrm{mg} / \mathrm{kg}$ & $79.1 \pm 2.3^{*}$ & $32.5 \pm 5.2 * *$ & $36.3 \pm 6.0 * *$ & $29.2 \pm 6.6^{*}$ & $0.71 \pm 0.03$ \\
\hline \multicolumn{6}{|l|}{ GBR12909 } \\
\hline Veh & $90.7 \pm 1.1$ & $14.6 \pm 2.1$ & $5.3 \pm 0.8$ & $6.7 \pm 1.1$ & $0.67 \pm 0.02$ \\
\hline $2.5 \mathrm{mg} / \mathrm{kg}$ & $91.2 \pm 1.2$ & $15.8 \pm 2.7$ & $4.8 \pm 0.7$ & $5.9 \pm 0.7$ & $0.67 \pm 0.02$ \\
\hline $5.0 \mathrm{mg} / \mathrm{kg}$ & $89.0 \pm 1.4$ & $11.6 \pm 1.8$ & $8.9 \pm 2.4$ & $7.9 \pm 1.6$ & $0.64 \pm 0.02 *$ \\
\hline $10.0 \mathrm{mg} / \mathrm{kg}$ & $85.3 \pm 2.3 * *$ & $10.2 \pm 1.9$ & $29.9 \pm 8.2 * *$ & $21.4 \pm 4.9 * *$ & $0.61 \pm 0.02 * *$ \\
\hline \multicolumn{6}{|c|}{ Atomoxetine } \\
\hline Veh & $91.0 \pm 1.5$ & $18.4 \pm 2.2$ & $6.4 \pm 1.5$ & $14.6 \pm 4.2$ & $0.73 \pm 0.03$ \\
\hline $0.3 \mathrm{mg} / \mathrm{kg}$ & $94.6 \pm 1.4$ & $25.8 \pm 2.5^{*}$ & $3.2 \pm 1.2$ & $11.0 \pm 2.3$ & $0.81 \pm 0.04 * *$ \\
\hline $1.0 \mathrm{mg} / \mathrm{kg}$ & $94.3 \pm 1.0$ & $33.4 \pm 3.0 * *$ & $3.5 \pm 0.9$ & $10.9 \pm 1.9$ & $0.84 \pm 0.04 * *$ \\
\hline $3.0 \mathrm{mg} / \mathrm{kg}$ & $94.5 \pm 1.6$ & $44.3 \pm 2.8^{* *}$ & $3.5 \pm 0.9$ & $10.2 \pm 2.4$ & $0.96 \pm 0.04 * *$ \\
\hline \multicolumn{6}{|l|}{ Citalopram } \\
\hline Veh & $91.7 \pm 1.0$ & $12.8 \pm 2.1$ & $5.1 \pm 0.8$ & $7.0 \pm 1.7$ & $0.66 \pm 0.02$ \\
\hline $0.3 \mathrm{mg} / \mathrm{kg}$ & $91.7 \pm 1.3$ & $15.8 \pm 2.6$ & $4.8 \pm 0.9$ & $7.1 \pm 1.1$ & $0.68 \pm 0.02$ \\
\hline $1.0 \mathrm{mg} / \mathrm{kg}$ & $92.2 \pm 1.2$ & $16.4 \pm 2.6$ & $2.6 \pm 0.4^{*}$ & $4.1 \pm 1.1$ & $0.69 \pm 0.02 *$ \\
\hline $3.0 \mathrm{mg} / \mathrm{kg}$ & $92.5 \pm 1.2$ & $16.6 \pm 2.2$ & $3.1 \pm 0.7$ & $7.4 \pm 1.5$ & $0.70 \pm 0.02 *$ \\
\hline
\end{tabular}

observed on errors of omission $[d f=15, t=-0.65$, NS and $d f=14, t=0.66, \mathrm{NS}]$.

Atomoxetine $(3 \mathrm{mg} / \mathrm{kg})$ reduced premature and perseverative responding under long ITI conditions (Fig. 2c) $[d f=$ $15, t=6.0, p<0.001$ and $d f=15, t=4.47, p<0.001$, respectively]. Additional comparisons revealed that all other parameters of 5-CSRTT were enhanced by atomoxetine under these conditions (Fig. 2c) [correct responses: $d f=15$, $t=-2.97, p=0.01$; omissions: $d f=15, t=-2.33 p<0.05$; response latency: $d f=15, t=-2.26, p<0.05]$.

Premature and perseverative responses were both reduced by citalopram $(1 \mathrm{mg} / \mathrm{kg})$ pretreatment under long ITI conditions (Fig. 2d) [premature responses: $d f=15, t=4.28$, $p=0.001$, perseverative responses: $d f=15, t=2.49, p<0.05]$. Under these conditions, citalopram did not affect accuracy, errors of omission and response latency [correct responses: $d f=15, t=-0.22$, NS, omissions: $d f=15, t=-0.19$, NS and response latency: $d f=15, t=1.26, \mathrm{NS}]$.

Effect of amphetamine and monoamine reuptake inhibitors on impulsive choice in the DRT

Overall, animals showed a delay-dependent decline in their choice behavior for the large, delayed reward [vehicle, delay: $F(4,48)=31.49, p<0.001]$. Amphetamine significantly enhanced the preference for the large delayed reward [dose: $F(3,36)=3.11, p<0.05$; dose $\times$ delay: $F(12,144)=1.33$, NS], and post-hoc analysis revealed that this effect was significant for all doses of amphetamine at the 40-s delay and for 0.5 and $1 \mathrm{mg} / \mathrm{kg}$ amphetamine at a delay of $60 \mathrm{~s}$ (Fig. 3a).

The selective DA reuptake inhibitor GBR12909 also increased the preference for the larger delayed reward [dose: $F(3,39)=11.07, p<0.001$; dose $\times$ delay: $F(12,156)=$ 2.29, $p=0.01]$. Post-hoc analysis of the data showed a significant effect of $10 \mathrm{mg} / \mathrm{kg}$ of GBR12909 on all delays, i.e., 10, 20, 40 and $60 \mathrm{~s}$ (Fig. 3b). At a dose of $5 \mathrm{mg} / \mathrm{kg}$, GBR12909 resulted in an increased preference for the large reward at the delay of 10 and $20 \mathrm{~s}$ (Fig. 3b).

The selective NA reuptake inhibitor atomoxetine did not alter choice behavior in the DRT at any delay [dose: $F(3,39)=$ 0.31 , NS; dose $\times$ delay: $F(12,156)=1.64, \mathrm{NS}$ ].

The selective 5-HT reuptake inhibitor citalopram also did not affect choice behavior in the DRT (Fig. 3d) [dose: $F(3,39)=$ 1.27, NS; dose $\times$ delay: $F(12,156)=1.11, \mathrm{NS}]$.

\section{Discussion}

In order to advance our understanding of the role of monoamine neurotransmission in impulse control, the 

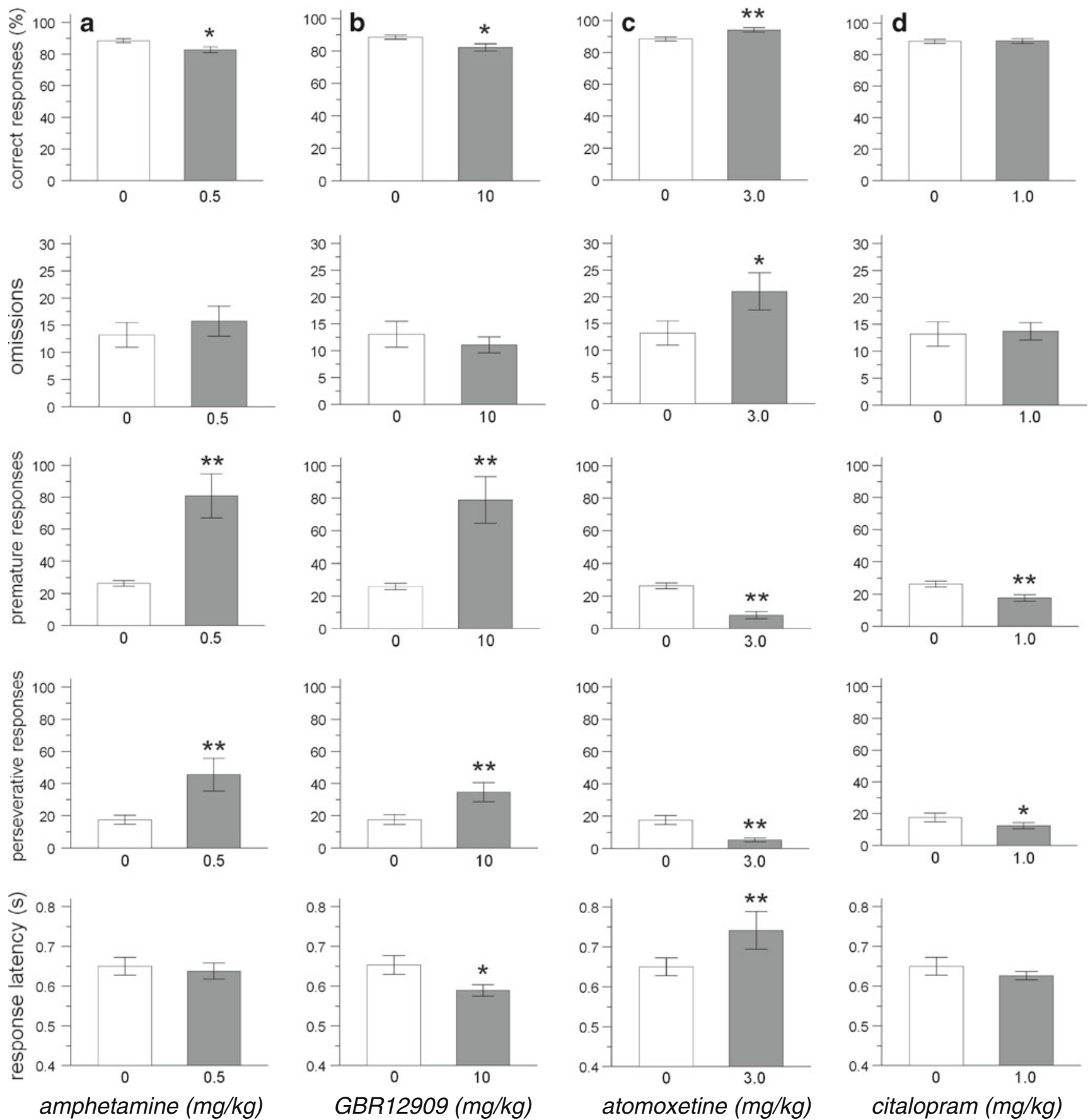

Fig. 2 Effects of amphetamine (a), the selective DA reuptake inhibitor GBR12909 (b), the selective NA reuptake inhibitor atomoxetine (c) and the selective 5-HT reuptake inhibitor citalopram (d) on 5-CSRTT performance under long ITI conditions (visual stimulus

present study investigated the effects of selective monoamine reuptake inhibitors on two behavioral dimensions of impulsivity, i.e., impulsive action in the 5-CSRTT and impulsive choice in the DRT. Besides comparing three selective monoamine reuptake inhibitors and amphetamine in two separate measures of impulsivity within a single study, we aimed to address several outstanding questions
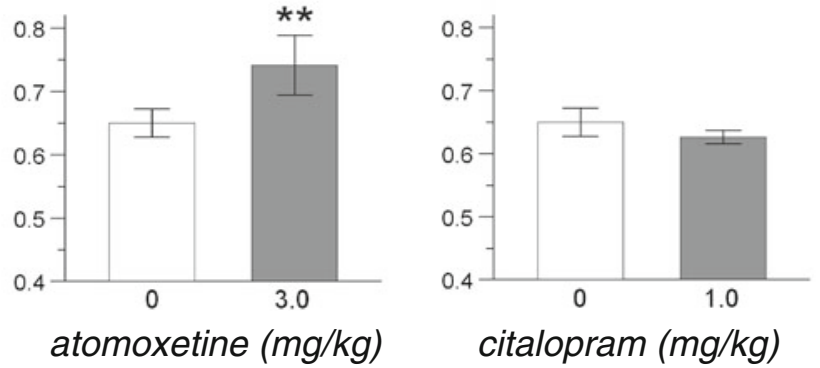

presented $7 \mathrm{~s}$ after trial initiation). In total, $n=15$ animals were included in the analysis. Asterisk indicates $p<0.05$ and two asterisks indicates $p<0.01$ compared to vehicle treatment (paired samples $t$ test). All data are expressed as mean \pm SEM

with regard to monoamine neurotransmission and impulsive behavior. Thus, we have shown that the 5-HT reuptake blocker citalopram selectively reduces premature responding in the 5-CSRTT but does not affect impulsive choice in the DRT. In addition, the NA reuptake inhibitor atomoxetine reduced impulsive action primarily when levels of premature responding were high (i.e., under a long ITI) but 
Fig. 3 Effects of amphetamine (a), the selective DA reuptake inhibitor GBR12909 (b), the selective NA reuptake inhibitor atomoxetine (c) and the selective 5-HT reuptake inhibitor citalopram (d) on the percentage choice for the large reinforcer in the delayed reward paradigm. In total, $n=13-15$ animals were included in the analysis. Asterisk indicates $p<0.05$ and two asterisks indicates $p<0.01$ compared to vehicle treatment (paired samples $t$-test). All data are expressed as mean $\pm \mathrm{SEM}$
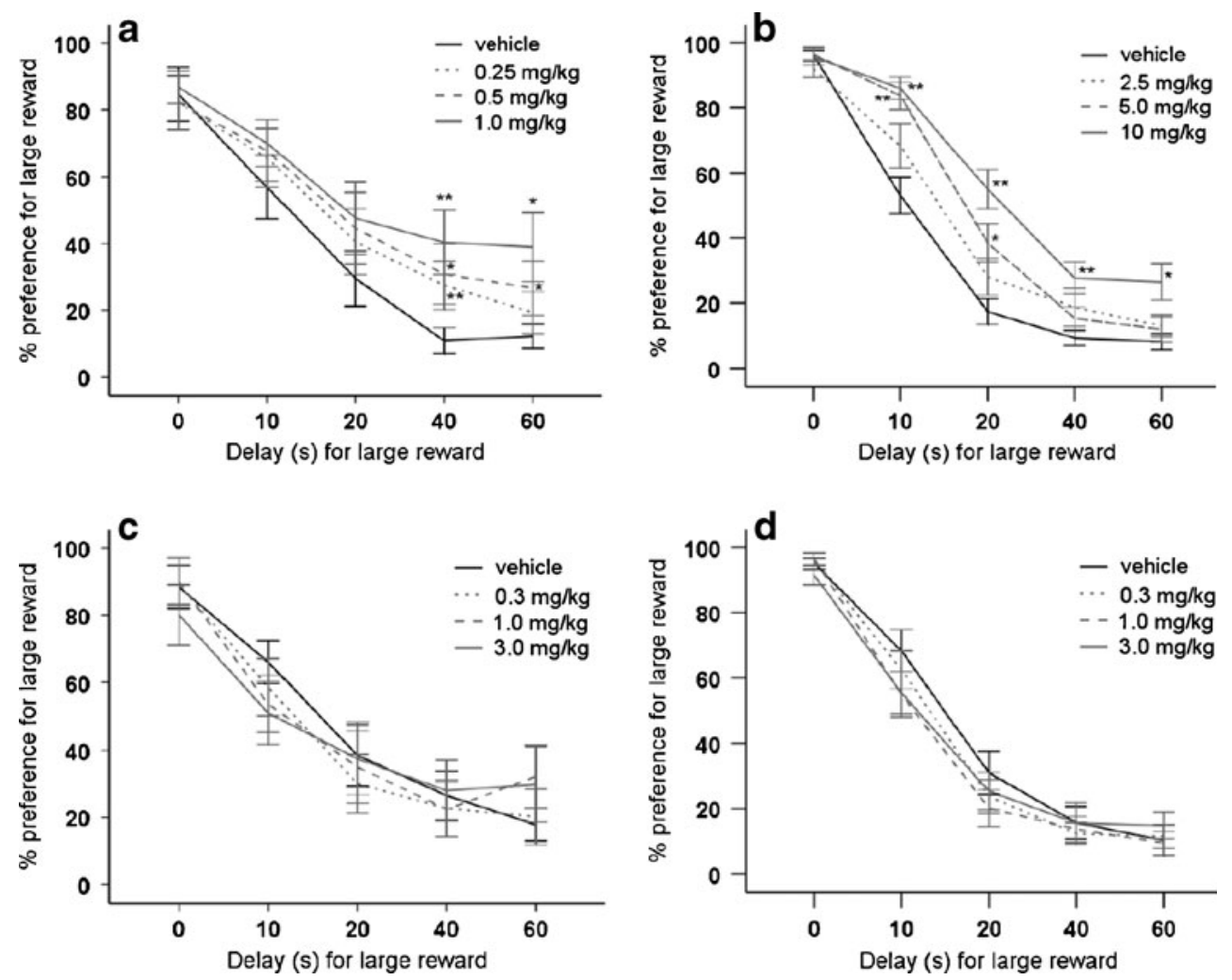

did not affect impulsive choice. Furthermore, using a long ITI in the 5-CSRTT, we show that amphetamine and the DA reuptake blocker GBR12909 enhance, and that atomoxetine and citalopram reduce impulsive action. Thus, the effects of these drugs on impulsive behavior were not qualitatively different under baseline and long ITI conditions. Consistent with previous findings, we also show that amphetamine and the selective dopamine reuptake blocker GBR12909 decreased impulsive choice.

Amphetamine has been consistently reported to disrupt inhibitory control, i.e., the ability to withhold responding in the 5-CSRTT (Cole and Robbins 1987; 1989; Harrison et al. 1997; Murphy et al. 2008; Paterson et al. 2011; Pattij et al. 2007; Sun et al. 2011; Van Gaalen et al. 2006a). Our findings confirmed this disinhibitory effect of amphetamine, which increased the number of premature responses in the 5-CSRTT at all doses tested $(0.25-1 \mathrm{mg} / \mathrm{kg})$. In addition to response inhibition, the 5-CSRTT provides several relatively independent measures of performance such as task efficiency, motivation and attentional capacity (Robbins 2002). Alongside its effects on premature responding, amphetamine also attenuated accuracy, enhanced perseverative responding, reduced response latency (at $0.5 \mathrm{mg} / \mathrm{kg}$ only) and had biphasic effects on errors of omission. The effects of amphetamine were comparable under baseline and long ITI conditions. Although not universally reported as effects of amphetamine in the 5CSRTT, the present profile of effects is highly comparable to previous reports (reduced accuracy: Cole and Robbins 1989; Harrison et al. 1997; Pattij et al. 2007; Sun et al. 2011; increased omissions: Cole and Robbins 1987; 1989; Harrison et al. 1997; Murphy et al. 2008; Sun et al. 2011; Van Gaalen et al. 2006a; and faster response latency: Cole and Robbins 1987; 1989; Harrison et al. 1997; Pattij et al. 2007).

Amphetamine increases extracellular levels of DA, NA, and, to a lesser extent, 5-HT by binding to monoamine transporters on the cell membrane and on intracellular neurotransmitter storage vesicles as a false substrate thereby promoting reverse transport of cytosolic transmitter stores (Seiden et al. 1993; Sulzer et al. 1995). Comparable to amphetamine, GBR12909 also enhanced premature responding, reduced accuracy, enhanced perseverative responding and reduced response latencies under both baseline and long ITI conditions. This indicates that the effects of amphetamine in the 5-CSRTT-except for the increases in errors of omission at the highest dose-are mediated by DA (Fernando et al. 2011; Seu et al. 2009; Van Gaalen et al. 2006a). Pharmacological studies have shown that the amphetamine-induced augmentation of premature responding in the 5-CSRTT largely depends on DA D2 receptor stimulation in the nucleus accumbens (Cole and Robbins 1989; Pattij et al. 2007; Van Gaalen et al. 2006a; 2009). Conversely, reducing DA neurotransmission using DA receptor antagonists or low doses of DA D2 receptor agonists, which suppress DA neurotransmission by stimu- 
lating presynaptic D2 autoreceptors, has been found to reduce impulsive action in the 5-CSRTT (Fernando et al. 2011; Koskinen and Sirvio 2001; Lecourtier and Kelly 2005; Passetti et al. 2003; Van Gaalen et al. 2006a; Winstanley et al. 2010). DA-mediated increases in the salience of the reward-related cues in the task and/or increased response vigor by amphetamine may explain its effects in the 5-CSRTT (Berridge and Robinson 1998; Cardinal et al. 2002). This results in a higher rate of performance reflected by a lower amount of errors of omission and faster response latency, albeit at the expense of task accuracy and reduced impulse control. This is consistent with the well-established effect of psychostimulant drugs on behavior, i.e., a general enhancement of the rate of behavioral performance causing short and simple behaviors to dominate the behavioral repertoire and cutting short of complex chains of behavior (Lyon and Robbins 1975). At the highest dose of amphetamine (1 mg/kg), this results in a more general disruption of task performance in the 5-CSRTT. Interestingly, the increase in errors of omission at this highest dose likely relies on NA rather than DA neurotransmission because this effect was mimicked by atomoxetine but not GBR12909. This indicates that at higher doses, the effects of amphetamine on 5CSRTT performance are mediated by increases in both DA and NA neurotransmission.

Neurobiological and pharmacological data provide evidence for the hypothesis that NA plays a key role in both the etiology and treatment of ADHD (Arnsten, 2009; Biederman and Spencer 1999). Moreover, clinical observations have shown that a subgroup of patients who do not respond to psychostimulants, such as amphetamine and methylphenidate, do respond to atomoxetine (Newcorn et al. 2008). Selective inhibition of NA reuptake by atomoxetine reduced premature responding in the 5-CSRTT under long ITI conditions. NA neurotransmission has been implicated in the regulation of behavior under novel or demanding circumstances (Aston-Jones and Cohen 2005; Cole and Robbins 1992; Dalley et al. 2001; McGaughy et al. 2002; Sirviö et al. 1993). In the 5-CSRTT, PFC NA levels rise when task contingencies are changed (Dalley et al. 2001), and cortically NA-depleted rats are slower to adapt to changing task requirements (Milstein et al. 2007). Our observation that atomoxetine was predominantly effective under (relatively) novel and challenging, long ITI conditions corresponds with these findings. Interestingly, previous studies that reported reduced impulsivity in the 5CSRTT under baseline conditions after atomoxetine treatment used a shorter stimulus duration $(0.5 \mathrm{~s}$ versus $1 \mathrm{~s}$ in the present study; Blondeau and Dellu-Hagedorn 2007; Robinson et al. 2008; Sun et al. 2011). Under these more demanding test conditions, levels of premature responses are higher, and performance may depend on NA signaling to a greater extent. An alternative, not necessarily inconsistent explanation, is that the absence of an effect of atomoxetine on impulsivity under baseline conditions in our study was due to a floor effect so that the increase in premature responses under long ITI conditions provided a larger window to observe a decrease in impulsivity. Interestingly, atomoxetine indeed seems to reduce impulsive action in the 5-CSRTT primarily in rats characterized by high levels of premature responses (Blondeau and Dellu-Hagedorn 2007; Fernando et al. 2011) or high levels of premature responding due to prolonged ITI durations (Navarra et al. 2008; Paterson et al. 2011). In these studies, no effect of selective blockade of NA by atomoxetine on impulsive action was observed in low impulsive rats (Fernando et al. 2011), efficient rats (Blondeau and Dellu-Hagedorn 2007) or at short intertrial interval durations (4- and 5-s ITI: Paterson et al. 2011; Navarra et al. 2008) consistently reflected by low baseline levels of premature responding.

Atomoxetine also increased errors of omission and lengthened response latencies, under both baseline and long ITI conditions, suggesting that this drug somewhat slowed down the performance in the 5-CSRTT. These effects of atomoxetine are consistent with previous findings with noradrenaline reuptake inhibitors, especially at higher doses (Blondeau and Dellu-Hagedorn 2007; Fernando et al. 2011; Navarra et al. 2008; Paine et al. 2007; Sun et al. 2011; Van Gaalen et al. 2006a). Motivational deficits do not likely underlie these increased omissions and response latencies because NA reuptake inhibitors have been shown to increase reinforcement rates in differential reinforcement of low responding schedules (O'Donnell et al. 2005). Interestingly, under the challenging long ITI conditions, accuracy was improved by systemic atomoxetine (see also Navarra et al. 2008) supporting the role of NA neurotransmission in behavioral vigilance (Arnsten 2004; Aston-Jones and Cohen 2005). Together, these data suggest that NA neurotransmission is particularly involved in the modulation of behavior in the 5-CSRTT under circumstances when task performance is suboptimal, either as a result of demanding task requirements or as a result of inherent individual differences in behavior. Increasing NA neurotransmission then leads to a more conservative pattern of responding whereby task accuracy and impulse control increase but speed of performance declines somewhat.

The serotonin reuptake inhibitor citalopram resulted in a decrease in premature responding in the 5-CSRTT at an intermediate dose of $1 \mathrm{mg} / \mathrm{kg}$. A similar improvement in impulse control was observed under long ITI conditions. In contrast to amphetamine, GBR12909 and atomoxetine, the effect of citalopram on premature responding was quite selective as accuracy and errors of omission were not affected. Our finding is in line with the observation that enhanced 5-HT transmission in 5-HT transporter knockout 
rats is associated with reduced premature responding in the 5-CSRTT (Homberg et al. 2007). Conversely, forebrain 5HT depletion significantly increases premature responding in the 5-CSRTT (Harrison et al. 1997; Winstanley et al. 2004). Together, these studies suggest that increasing 5-HT activity may be a possible mechanism for attenuation of impulsive action. In vivo microdialysis within the medial prefrontal cortex has shown a positive relationship between premature responding and basal 5-HT levels although no alteration in 5-HT efflux during task performance was found (Dalley et al. 2002). These results indicate a role for tonic 5-HT levels in the prefrontal cortex in impulsive regulation in the 5-CSRTT. However, 5-HT depletion using 5,7-DHT infusion into the medial prefrontal cortex did not affect impulsive action in the 5-CSRTT (Fletcher et al. 2009). Thus, the role of 5-HT in impulse action is not straightforward, which is likely related to the great diversity of 5-HT receptors, and the fact that 5-HT modulates impulsive action through different brain regions (Eagle and Baunez 2010; Pattij and Vanderschuren 2008).

In contrast to its effects on impulsive behavior in the 5CSRTT, amphetamine had beneficial effects on impulsive choice, exemplified by the enhanced ability of the animals to choose a large, delayed reward instead of a small, immediate reward. Our finding is in keeping with previous studies in mice, rats and humans (Barbelivien et al. 2008; De Wit et al. 2002; Isles et al. 2003; Richards et al. 1999; Van Gaalen et al. 2006b; Wade et al. 2000; Winstanley et al. 2003) although this effect of amphetamine is found to be dose-, baselineand context-dependent (Barbelivien et al. 2008; Cardinal et al. 2000; Evenden and Ryan 1996; Isles et al. 2003). In this study, we showed that impulsive choice was decreased after blockade of DA by GBR12909 but not selective blockade of NA or 5-HT by atomoxetine or citalopram, respectively. An important regulatory role of DA in impulsive choice has been proposed before (Wade et al. 2000; Van Gaalen et al. 2006b) as the improved impulsive choice by amphetamine was blocked by the DA D2 receptor antagonist eticlopride (Van Gaalen et al. 2006b).

In the present study, atomoxetine did not affect impulsive choice. In agreement with our findings, Sun et al. (2011) found no effect on impulsive choice following atomoxetine administration. In contrast, Robinson et al. (2008) reported that atomoxetine reduced impulsive choice whereby the increase in percentage choice for the large reward after atomoxetine treatment was most pronounced at the shorter delays. The somewhat less selective NA reuptake blocker desipramine had no consistent effect in the DRT (Van Gaalen et al. 2006b). Together, these data suggest that acute enhancement of NA neurotransmission has, at best, modest effects on impulsive choice in a delayed reward task.

In vivo microdialysis experiments have shown that 5-HT release within the medial prefrontal cortex correlates with performance in the DRT (Winstanley et al. 2006) indicating that 5-HT release is essential for proper delay discounting judgments. However, inconsistent effects of forebrain 5-HT depletions on impulsive choice have been found (Bizot et al. 1999; Mobini et al. 2000; Winstanley et al. 2003; 2004; Wogar et al. 1993). Likewise, inconsistent effects of 5-HT depletion have been found in humans as tryptophan depletion increased delay discounting in healthy volunteers in one study (Schweighofer et al. 2008) but not another (Crean et al. 2002). In the present study, selective inhibition of 5-HT reuptake by citalopram did not affect choice behavior in the delayed reward task. In agreement with our findings, Evenden and Ryan (1996) found that the tolerance to delay of gratification was not affected by acute administration of citalopram or imipramine. Early studies on the neural mechanisms of impulsive behavior have implicated low levels of 5-HT in impulsivity (Linnoila et al. 1983; Soubrié 1986). Together with previous findings discussed here, our data indicate that elevation of 5-HT levels by SSRIs has a beneficial effect on impulsive action but not impulsive choice suggesting that the early association of 5-HT with impulsivity relates more to the former than to the latter.

The present study aimed to pinpoint the separate roles of three monoamine neurotransmitters in two forms of impulsive behavior using selective DA, NA and 5-HT reuptake blockers. Two limitations to this approach should be mentioned. First, although GBR12909, atomoxetine and citalopram display low affinity for the other monoamine transporters (Fone and Nutt 2005; Rothman et al. 2001), transporter-selective reuptake inhibitors are not necessarily transmitter-selective reuptake inhibitors. DA reuptake in the striatum depends primarily on the DA transporter, whereas DA reuptake in the prefrontal cortex depends on both the NA transporter and the DA transporter due to the low density of the DA transporter in this area (Carboni et al. 2006; Morón et al. 2002; Tanda et al. 1997). Atomoxetine, therefore, indirectly boosts prefrontal cortical DA via its effects on the NA transporter but it does not modulate DA levels in the striatum (Bymaster et al. 2002). Thus, a contribution of prefrontal DA to the effects of atomoxetine in the 5-CSRTT cannot be excluded. However, the COMT inhibitor tolcapone that selectively modulates DA, but not NA, did not attenuate impulsive action in rats that exhibited suboptimal 5-CSRTT performance suggesting that cortical DA does not contribute to the effects of atomoxetine on impulsive action (Paterson et al. 2011). Second, through their downstream effects, increased synaptic DA, NA and 5-HT levels can indirectly alter the activity of other neurotransmitter systems (e.g., Di Giovanni et al. 1999; Vanderschuren et al. 1999) so that coordinated activity of multiple neurotransmitter systems mediates adaptive behavior. For example, with regard to impulse control, 5-HT-DA interactions have been shown to be involved in impulsive 
choice in rats. Thus, forebrain 5-HT lesions attenuated the ability of amphetamine to decrease impulsive behavior in a delay-discounting task, particularly in rats with high baseline levels of impulsivity, but did not themselves alter delaydiscounting performance (Winstanley et al. 2003). Therefore, involvement of neurotransmitters other than DA, NA and 5HT, respectively, in the behavioral effects of GBR12909, atomoxetine and citalopram cannot be excluded.

In conclusion, the neuropharmacological manipulations presented here indicate a differential contribution of DA, NA and 5-HT in the modulation of two dimensions of impulsivity. Inhibition of the reuptake of DA exerted opposite effects on impulsive action (increase) and impulsive choice (decrease), whereas inhibition of NA and 5-HT reuptake reduced impulsive action but not impulsive choice. The current study, therefore, supports the well-established notion of the heterogenous nature of impulsivity (Dalley et al. 2011; Eagle and Baunez 2010; Evenden 1999; Pattij and Vanderschuren 2008). The existence of independent processes of impulse control is exemplified in the psychiatric population, although it is difficult to relate certain forms of impulsivity with particular disorders (Moeller et al. 2001; Solanto et al. 2001; Sonuga-Barke 2003). Nevertheless, deficits in one of the subtypes of impulsivity or genetic variation in monoamine signaling (e.g., Colzato et al. 2010; Hamidovic et al. 2009) may contribute to the differential responsiveness and effectiveness of drug treatments in impulse control disorders. As such, understanding the contribution of different neurotransmitter systems to distinct forms of impulsivity may contribute to the development of selectively tailored pharmacotherapeutic treatments of impulse control disorders.

Acknowledgements This study was supported by the National Institute on Drug Abuse Grant R01 DA022628 (L.J.M.J.V.). We thank Tommy Pattij for sharing the program codes for the tasks.

Open Access This article is distributed under the terms of the Creative Commons Attribution Noncommercial License which permits any noncommercial use, distribution, and reproduction in any medium, provided the original author(s) and source are credited.

\section{References}

American Psychiatric Association (2000) Diagnostic and statistical manual of mental disorders, Ed 4, Text Revision. American Psychiatric Association, Washington, DC

Arnsten AFT (2004) Adrenergic targets for the treatment of cognitive deficits in schizophrenia. Psychopharmacology 174:25-31

Aston-Jones G, Cohen JD (2005) An integrative theory of locus coeruleus-norepinephrine function: adaptive gain and optimal performance. Annu Rev Neurosci 28:403-450

Audrain-McGovern J, Rodriguez D, Epstein LH, Cuevas J, Rodgers K, Wileyto EP (2009) Does delay discounting play an etiological role in smoking or is it a consequence of smoking? Drug Alcohol Depend 103:99-106
Barbelivien A, Billy E, Lazarus C, Kelche C, Majchrzak M (2008) Rats with different profiles of impulsive choice behavior exhibit differences in responses to caffeine and d-amphetamine and in medial prefrontal cortex 5-HT utilization. Behav Brain Res 187:273-283

Bari A, Eagle DM, Mar AC, Robinson ESJ, Robbins TW (2009) Dissociable effects of noadrenaline, dopamine and serotonin uptake blockade on stop task performance in rats. Psychopharmacology 205:273-283

Berridge KC, Robinson TE (1998) What is the role of dopamine in reward: hedonic impact, reward learning, or incentive salience? Brain Res Rev 28:309-369

Biederman J, Faraone SV (2005) Attention-deficit hyperactivity disorder. Lancet 366:237-248

Biederman J, Spencer T (1999) Attention-deficit/hyperactivity disorder (ADHD) as a noradrenergic disorder. Review Biol Psychiatry 46:1234-1242

Bizot JC, Le Bihan C, Puech AJ, Hamon M, Thiébot M (1999) Serotonin and tolerance to delay of reward in rats. Psychopharmacology 146:400-412

Blondeau C, Dellu-Hagedorn F (2007) Dimensional analysis of ADHD subtypes in rats. Biol Psychiatry 61:1340-1350

Bolden-Watson C, Richelson E (1993) Blockade by newly-developed antidepressants of biogenic amine uptake into rat brain synaptosomes. Life Sci 52:1023-1029

Bymaster FP, Katner JS, Nelson DL, Hemrick-Luecke SK, Threlkeld PG, Heiligenstein JH, Morin SM, Gehlert DR, Perry KW (2002) Atomoxetine increases extracellular levels of norepinephrine and dopamine in prefrontal cortex of rat: a potential mechanism for efficacy in attention deficit/hyperactivity disorder. Neuropsychopharmacology 27:699-711

Carboni E, Silvagni A, Vacca C, Di Chiara G (2006) Cumulative effect of norepinephrine and dopamine carrier blockade on extracellular dopamine increase in the nucleus accumbens shell, bed nucleus of stria terminalis and prefrontal cortex. J Neurochem 96:473-481

Cardinal RN, Robbins TW, Everitt BJ (2000) The effects of damphetamine, chlordiazepoxide, alpha-flupenthixol and behavioural manipulations on choice of signalled and unsignalled delayed reinforcement in rats. Psychopharmacology 152:362 375

Cardinal RN, Parkinson JA, Hall J, Everitt BJ (2002) Emotion and motivation: the role of the amygdala, ventral striatum, and prefrontal cortex. Neurosci Biobehav Rev 26:321-352

Carli M, Robbins TW, Evenden JL, Everitt BJ (1983) Effects of lesions to ascending noradrenergic neurones on performance of a 5 -choice serial reaction task in rats; implications for theories of dorsal noradrenergic bundle function based on selective attention and arousal. Behav Brain Res 9:361-380

Chamberlain SR, Sahakian BJ (2007) The neuropsychiatry of impulsivity. Curr Opin Psychiatry 20:255-261

Coccaro EF, Kavoussi RJ (1997) Fluoxetine and impulsive aggressive behavior in personality-disordered subjects. Arch Gen Psychiatry 54:1081-8

Cole BJ, Robbins TW (1987) Amphetamine impairs the discriminative performance of rats with dorsal noradrenergic bundle lesions on a 5-choice serial reaction time task: new evidence for central dopaminergic-noradrenergic interactions. Psychopharmacology 91:458-466

Cole BJ, Robbins TW (1989) Effects of 6-hydroxydopamine lesions of the nucleus accumbens septi on performance of a 5-choice serial reaction time task in rats: implications for theories of selective attention and arousal. Behav Brain Res 33:165-179

Cole BJ, Robbins TW (1992) Forebrain norepinephrine: role in controlled information processing in the rat. Neuropsychopharmacology 7:129-142 
Colzato LS, van den Wildenberg WP, Van der Does AJ, Hommel B (2010) Genetic markers of striatal dopamine predict individual differences in dysfunctional, but not functional impulsivity. Neuroscience 170:782-788

Crean J, Richards JB, de Wit H (2002) Effect of tryptophan depletion on impulsive behavior in men with or without a family history of alcoholism. Behav Brain Res 136:349-357

Dalley JW, McGaughy J, O'Connell MT, Cardinal RN, Levita L, Robbins TW (2001) Distinct changes in cortical acetylcholine and noradrenaline efflux during contingent and noncontingent performance of a visual attentional task. J Neurosci 21:49084914

Dalley JW, Theobald DE, Eagle DM, Passetti F, Robbins TW (2002) Deficits in impulse control associated with tonically-elevated serotonergic function in rat prefrontal cortex. Neuropsychopharmacology 26:716-728

Dalley JW, Fryer TD, Brichard L, Robinson ES, Theobald DE, Lääne K, Peña Y, Murphy ER, Shah Y, Probst K, Abakumova I, Aigbirhio FI, Richards HK, Hong Y, Baron JC, Everitt BJ, Robbins TW (2007) Nucleus accumbens D2/3 receptors predict trait impulsivity and cocaine reinforcement. Science 315:126770

Dalley JW, Everitt BJ, Robbins TW (2011) Impulsivity, compulsivity, and top-down cognitive control. Neuron 69:680-694

De Wit H, Enggasser JL, Richards JB (2002) Acute administration of d-amphetamine decreases impulsivity in healthy volunteers. Neuropsychopharmacology 27:813-825

Di Giovanni G, De Deurwaerdére P, Di Mascio M, Di Matteo V, Esposito E, Spampinato U (1999) Selective blockade of serotonin-2 $\mathrm{C} / 2 \mathrm{~B}$ receptors enhances mesolimbic and mesostriatal dopaminergic function: a combined in vivo electrophysiological and microdialysis study. Neuroscience 91:587-597

Diergaarde L, Pattij T, Poortvliet I, Hogenboom F, de Vries W, Schoffelmeer ANM, De Vries TJ (2008) Impulsive choice and impulsive action predict vulnerability to distinct stages of nicotine seeking in rats. Biol Psychiatry 63:301-308

Eagle DM, Baunez C (2010) Is there an inhibitory-response-control system in the rat? Evidence from anatomical and pharmacological studies of behavioral inhibition. Neurosci Biobehav Rev 34:50-72

Elia J, Ambrosini PJ, Rapoport JL (1999) Treatment of attentiondeficithyperactivity disorder. N Engl J Med 340:780-788

Evenden JL (1999) Varieties of impulsivity. Psychopharmacology 146:348-361

Evenden JL, Ryan CN (1996) The pharmacology of impulsive behaviour in rats: the effects of drugs on response choice with varying delays of reinforcement. Psychopharmacology 128:161170

Fernando AB, Economidou D, Theobald DE, Zou MF, Newman AH, Spoelder M, Caprioli D, Moreno M, Hipólito L, Aspinall AT, Robbins TW, Dalley JW (2011) Modulation of high impulsivity and attentional performance in rats by selective direct and indirect dopaminergic and noradrenergic receptor agonists. Psychopharmacology. doi:10.1007/s00213-011-2408-Z

Fletcher PJ, Chambers JW, Rizos Z, Chintoh AF (2009) Effects of 5HT depletion in the frontal cortex or nucleus accumbens on response inhibition measured in the 5-choice serial reaction time test and on a DRL schedule. Behav Brain Res 201:88-98

Fone KC, Nutt DJ (2005) Stimulants: use and abuse in the treatment of attention deficit hyperactivity disorder. Curr Opin Pharmacol 5:87-93

Hamidovic A, Dlugos A, Skol A, Palmer AA, de Wit H (2009) Evaluation of genetic variability in the dopamine receptor D2 in relation to behavioral inhibition and impulsivity/sensation seeking: an exploratory study with d-amphetamine in healthy participants. Exp Clin Psychopharmacol 17:374-83
Harrison AA, Everitt BJ, Robbins TW (1997) Central 5-HT depletion enhances impulsive responding without affecting the accuracy of attentional performance: interactions with dopaminergic mechanisms. Psychopharmacology 133:329-42

Hollander E, Rosen J (2000) Impulsivity. J Psychopharmacol 14:S3944

Homberg JR, Pattij T, Janssen MC, Ronken E, De Boer SF, Schoffelmeer AN, Cuppen E (2007) Serotonin transporter deficiency in rats improves inhibitory control but not behavioural flexibility. Eur J Neurosci 26:2066-2073

Isles AR, Humby T, Wilkinson LS (2003) Measuring impulsivity in mice using a novel operant delayed reinforcement task: effects of behavioural manipulations and d-amphetamine. Psychopharmacology 170:376-82

Koskinen T, Sirvio J (2001) Studies on the involvement of the dopaminergic system in the 5-HT2 agonist (DOI)-induced premature responding in a five-choice serial reaction time task. Brain Res Bull 54:65-75

Kratochvil CJ, Wilens TE, Greenhill LL, Gao H, Baker KD, Feldman PD, Gelowitz DL (2006) Effects of long-term atomoxetine treatment for young children with attentiondeficit/hyperactivity disorder. J Am Acad Child Adolesc Psychiatry 45:919-927

Kuczenski R, Segal D (1989) Concomitant characterization of behavioral and striatal neurotransmitter response to amphetamine using in vivo microdialysis. J Neurosci 9:2051-2065

Kuczenski R, Segal DS, Cho AK, Melega W (1995) Hippocampus norepinephrine, caudate dopamine and serotonin, and behavioral responses to the stereoisomers of amphetamine and methamphetamine. J Neurosci 15:1308-1317

Kutcher S, Aman M, Brooks SJ, Buitelaar J, van Daalen E, Fegert J, Findling RL, Fisman S, Greenhill LL, Huss M, Kusumakar V, Pine D, Taylor E, Tyano S (2004) International consensus statement on attention-deficit/hyperactivity disorder (ADHD) and disruptive behaviour disorders (DBDs): clinical implications and treatment practice suggestions. Eur Neuropsychopharmacol 14:11-28

Lecourtier L, Kelly PH (2005) Bilateral lesions of the habenula induce attentional disturbances in rats. Neuropsychopharmacology 30:484-496

Linnoila M, Virkkunen M, Scheinin M, Nuutila A, Rimon R, Goodwin FK (1983) Low cerebrospinal-fluid 5-hydroxyindoleacetic acid concentration differentiates impulsive from non-impulsive violent behavior. Life Sci 33:2609-2614

Logue AW (1988) Research on self-control: an integrating framework. Behav Brain Sci 11:665-709

Lyon M, Robbins TW (1975) The action of central nervous system stimulant drugs: a general theory concerning amphetamine effects. In: Essman WB, Valzelli L (eds) Current developments in psychopharmacology. Spectrum, New York, pp 79-163

McDonald J (2009) Handbook of biological statistics. Sparky House Publishing, Baltimore, Ed, 2

McGaughy J, Dalley JW, Morrison CH, Everitt BJ, Robbins TW (2002) Selective behavioral and neurochemical effects of cholinergic lesions produced by intrabasalis infusions of 192 IgG-saporin on attentional performance in a five-choice serial reaction time task. J Neurosci 22:1905-1913

Milstein JA, Lehmann O, Theobald DE, Dalley JW, Robbins TW (2007) Selective depletion of cortical noradrenaline by antidopamine beta-hydroxylase-saporin impairs attentional function and enhances the effects of guanfacine in the rat. Psychopharmacology 190:51-63

Mobini S, Chiang TJ, Ho MY, Bradshaw CM, Szabadi E (2000) Effects of central 5-hydroxytryptamine depletion on sensitivity to delayed and probabilistic reinforcement. Psychopharmacology 152:390-397 
Moeller FG, Barratt ES, Dougherty DM, Schmitz JM, Swann AC (2001) Psychiatric aspects of impulsivity. Am J Psychiatry 158:1783-1793

Morón JA, Brockington A, Wise RA, Rocha BA, Hope BT (2002) Dopamine uptake through the norepinephrine transporter in brain regions with low levels of the dopamine transporter: evidence from knock-out mouse lines. J Neurosci 22:389-395

Murphy ER, Robinson ES, Theobald DE, Dalley JW, Robbins TW (2008) Contrasting effects of selective lesions of nucleus accumbens core or shell on inhibitory control and amphetamine-induced impulsive behaviour. Eur J Neurosci 28:353-363

Navarra R, Graf R, Huang Y, Logue S, Comery T, Hughes Z, Day M (2008) Effects of atomoxetine and methylphenidate on attention and impulsivity in the 5-choice serial reaction time test. Prog Neuropsychopharmacol Biol Psychiatry 32:34-41

Newcorn JH, Kratochvil CJ, Allen AJ, Casat CD, Ruff DD, Moore RJ, Michelson D (2008) Atomoxetine and osmotically released methylphenidate for the treatment of attention deficit hyperactivity disorder: acute comparison and differential response. Am J Psychiatry 165:721-730

Nigg JT, Wong MM, Martel MM, Jester JM, Puttler LI, Glass JM, Adams KM, Fitzgerald HE, Zucker RA (2006) Poor response inhibition as a predictor of problem drinking and illicit drug use in adolescents at risk for alcoholism and other substance use disorders. J Am Acad Child Adolesc Psychiatry 45:468-475

O'Donnell JM, Marek GJ, Seiden LS (2005) Antidepressant effects assessed using behavior maintained under a differentialreinforcement-of-low-rate (DRL) operant schedule. Neurosci Biobehav Rev 29:785-798

Paine TA, Tomasiewicz HC, Zhang K, Carlezon WA (2007) Sensitivity of the five-choice serial reaction time task to the effects of various psychotropic drugs in Sprague-Dawley rats. Biol Psychiatry 62:687-93

Passetti F, Levita L, Robbins TW (2003) Sulpiride alleviates the attentional impairments of rats with medial prefrontal cortex lesions. Behav Brain Res 138:59-69

Paterson NE, Ricciardi J, Wetzler C, Hanania T (2011) Sub-optimal performance in the 5-choice serial reaction time task in rats was sensitive to methylphenidate, atomoxetine and D-amphetamine, but unaffected by the COMT inhibitor tolcapone. Neurosci Res 69:41-50

Pattij T, Vanderschuren LJMJ (2008) The neuropharmacology of impulsive behaviour. Trends Pharmacol Sci 29:192-199

Pattij T, Janssen MCW, Vanderschuren LJMJ, Schoffelmeer ANM, van Gaalen MM (2007) Involvement of dopamine $D(1)$ and $D(2)$ receptors in the nucleus accumbens core and shell in inhibitory response control. Psychopharmacology 191:587-598

Perry JL, Larson EB, German JP, Madden GJ, Carroll ME (2005) Impulsivity (delay discounting) as a predictor of acquisition of IV cocaine self-administration in female rats. Psychopharmacology 178:193-201

Poulos CX, Le AD, Parker JL (1995) Impulsivity predicts individual susceptibility to high levels of alcohol self-administration. Behav Pharmacol 6:810-814

Richards JB, Sabol KE, de Wit H (1999) Effects of methamphetamine on the adjusting amount procedure, a model of impulsive behavior in rats. Psychopharmacology 146:432-439

Ritz MC, Kuhar MJ (1989) Relationship between self-administration of amphetamine and monoamine receptors in brain: comparison with cocaine. J Pharmacol Exp Ther 248:1010-1017

Robbins TW (2002) The 5-choice serial reaction time task: behavioural pharmacology and functional neurochemistry. Psychopharmacology 163:362-380

Robinson ES, Eagle DM, Mar AC, Bari A, Banerjee G, Jiang X, Dalley JW, Robbins TW (2008) Similar effects of the selective noradrenaline reuptake inhibitor atomoxetine on three distinct forms of impulsivity in the rat. Neuropsychopharmacology 33:1028-1037

Rothman RB, Baumann MH, Dersch CM, Romero DV, Rice KC, Carroll FI, Partilla JS (2001) Amphetamine-type central nervous system stimulants release norepinephrine more potently than they release dopamine and serotonin. Synapse 39:32-41

Schweighofer N, Bertin M, Shishida K, Okamoto Y, Tanaka SC, Yamawaki S, Doya K (2008) Low-serotonin levels increase delayed reward discounting in humans. J Neurosci 28:4528-4532

Seiden LS, Sabol KE, Ricaurte GA (1993) Amphetamine: effects on catecholamine systems and behavior. Annu Rev Pharmacol Toxicol 33:639-677

Seu E, Lang A, Rivera RJ, Jentsch JD (2009) Inhibition of the norepinephrine transporter improves behavioral flexibility in rats and monkeys. Psychopharmacology 202:505-519

Simpson D, Perry CM (2003) Atomoxetine. Paediatr Drugs 5:407415

Sirviö J, Jäkälä P, Mazurkiewicz M, Haapalinna A, Riekkinen P Jr, Riekkinen PJ (1993) Dose- and parameter-dependent effects of atipamezole, an alpha 2-antagonist, on the performance of rats in a five-choice serial reaction time task. Pharmacol Biochem Behav 45:123-129

Solanto MV, Abikoff H, Sonuga-Barke E, Schachar R, Logan GD, Wigal T, Hechtman L, Hinshaw S, Turkel E (2001) The ecological validity of delay aversion and response inhibition as measures of impulsivity in $\mathrm{AD} / \mathrm{HD}$ : a supplement to the NIMH multi-modal treatment study of AD/HD. J Abnorm Child Psychol 29:215-228

Sonuga-Barke EJS (2003) The dual pathway model of AD/HD: an elaboration of neurodevelopmental characteristics. Neurosci Biobehav Rev 27:593-604

Soubrié P (1986) Reconciling the role of central serotonin neurons in human and animal behavior. Behav Brain Sci 9:319-364

Spencer TJ, Biederman J, Wilens TE, Faraone SV (2002) Novel treatments for attention-deficit/hyperactivity disorder in children. J Clin Psychiatry 12:16-22

Sulzer D, Chen TK, Lau YY, Kristensen H, Rayport S, Ewing A (1995) Amphetamine redistributes dopamine from synaptic vesicles to the cytosol and promotes reverse transport. J Neurosci 15:4102-4108

Sun H, Cocker PJ, Zeeb FD, Winstanley CA (2011) Chronic atomoxetine treatment during adolescence decreases impulsive choice, but not impulsive action, in adult rats and alters markers of synaptic plasticity in the orbitofrontal cortex. Psychopharmacology doi:10.1007/s00213-011-2419-9

Tanda G, Pontieri FE, Frau R, Di Chiara G (1997) Contribution of blockade of the noradrenaline carrier to the increase of extracellular dopamine in the rat prefrontal cortex by amphetamine and cocaine. Eur J Neurosci 9:2077-2085

Van Gaalen MM, Brueggeman RJ, Bronius PFC, Schoffelmeer ANM, Vanderschuren LJMJ (2006a) Behavioral disinhibition requires dopamine receptor activation. Psychopharmacology 187:73-85

Van Gaalen MM, van Koten R, Schoffelmeer ANM, Vanderschuren LJMJ (2006b) Critical involvement of dopaminergic neurotransmission in impulsive decision making. Biol Psychiatry 60:66-73

Van Gaalen MM, Unger L, Jongen-Rêlo AL, Schoemaker H, Gross G (2009) Amphetamine decreases behavioral inhibition by stimulation of dopamine D2, but not D3, receptors. Behav Pharmacol 20:484-491

Vanderschuren LJMJ, Wardeh G, De Vries TJ, Mulder AH, Schoffelmeer ANM (1999) Opposing role of dopamine D1 and D2 receptors in modulation of rat nucleus accumbens noradrenaline release. $J$ Neurosci 19:4123-4131

Wade TR, de Wit H, Richards JB (2000) Effects of dopaminergic drugs on delayed reward as a measure of impulsive behavior in rats. Psychopharmacology 150:90-101 
Wilens TE, Newcorn JH, Kratochvil CJ, Gao H, Thomason CK, Rogers AK, Feldman PD, Levine LR (2006) Long-term atomoxetine treatment in adolescents with attention-deficit/hyperactivity disorder. J Pediatr 149:112-119

Winstanley CA (2011) The utility of rat models of impulsivity in developing pharmacotherapies for impulse control disorders. Br J Pharmacol 164:1301-1321

Winstanley CA, Dalley JW, Theobald DEH, Robbins TW (2003) Global 5-HT depletion attenuates the ability of amphetamine to decrease impulsive choice on a delay-discounting task in rats. Psychopharmacology 170:320-331

Winstanley CA, Theobald DE, Dalley JW, Glennon JC, Robbins TW (2004) 5-HT2A and 5-HT2C receptor antagonists have opposing effects on a measure of impulsivity: interactions with global 5-HT depletion. Psychopharmacology 176:376-385

Winstanley CA, Eagle DM, Robbins TW (2006) Behavioral models of impulsivity in relation to ADHD: translation between clinical and preclinical studies. Clin Psychol Rev 26:379-395

Winstanley CA, Zeeb FD, Bedard A, Fu K, Lai B, Steele C, Wong AC (2010) Dopaminergic modulation of the orbitofrontal cortex affects attention, motivation and impulsive responding in rats performing the five-choice serial reaction time task. Behav Brain Res 210:263-272

Wogar MA, Bradshaw CM, Szabadi E (1993) Effect of lesions of the ascending 5-hydroxytryptaminergic pathways on choice between delayed reinforcers. Psychopharmacology 111:239-43 